\title{
THE STATE OF TRYPTOPHAN-CONTAINING SITES OF HUMAN, BOVINE AND RABBIT PLASMINOGENS WITH CHANGING SOLUTION pHs
}

\author{
V. N. Nikandrov, G. V. Vororyova and N. V. Demidchik \\ Laboratory of Biochemistry, Byelorussian Research Institute of Epidemiology and Microbiology, \\ Minsk 220050, Byelorussia
}

(Received 27 July 1993)

\begin{abstract}
The state of tryptophan-containing sites is proved to be stable by intrinsic tryptophan fluorescence with pH 5-8, 7-9, and 6-9 in human, rabbit and bovine plasminogen molecules, respectively.

2. With $\mathrm{pH}<5.0$ tryptophan-containing sites of human zymogen (in contrast to rabbit and bovine ones) undergo conformational transitions.

3. With the shift of solution $\mathrm{pH}$ from 9 to 12 tryptophan-containing sites of human and rabbit plasminogens are partially disorganized, while tryptophanyls become more available for solvent.

4. Tryptophan-containing sites of bovine plasminogen molecules are less mobile in structure during changes of solution $\mathrm{pH}$.
\end{abstract}

\section{INTRODUCTION}

Fibrinolysis plays a very important role in several physiologic and pathologic processes, such as histogenesis and tissue differentiation, ovulation and embryo implantation, malignancy and metastatic spread of tumors, inflammation etc. (Kristensen et al., 1984; Laiho and Keski-Oja, 1989; Niedbala and Sartorelli, 1989). The key reaction in fibrinolysis is plasminogen $(\mathrm{Pg})$ transformation into plasmin, an active serine proteinase, by so-called "proteinase" or "non-proteinase" pathways (Jackson et al., 1980).

The mechanism of Pg activation by a nonproteinase pathway remains a subject of many years of research, but is still far from clear. One of the results of this activation is action on $\mathrm{Pg}$ by streptokinase (SK), a protein factor, synthesized by $\beta$-haemolytic streptococci, of $\sim 50 \mathrm{kDa}$ molecular weight and devoid of any hydrolase activity (Reddy, 1988). The SK activating function is characterized by species specificity: it activates human, canine, and rabbit Pgs but not sheep, bovine or mouse Pgs (Ablondi and Hagan, 1958; Wulf and Mertz, 1969; Castellino, 1979). SK also forms a comparatively stable complex with human $\mathrm{Pg}$ or human plasmin, which is considered a carrier of activating function, and the formation of this complex is considered the major condition for activation to occur (Castellino, 1979; Reddy, 1988). Accordingly, SK does not form such complexes with sheep and bovine Pgs (Summaria et al., 1974; Paoni and Castellino, 1979). However, there is one exception from this general rule: $S K$ activates native rabbit $\mathbf{P g}$, but does not form a stable complex with it (Schick and Castellino, 1973).

The reasons for the species specificity of SK action were sought after by looking at peculiarities of zymogen structures (Ablondi and Hagan, 1957). However, until the present time differences in structural organization between human and animal Pg molecules have not been clearly identified. In previous studies we determined states of tyrosine and tryptophan residues, secondary and tertiary structures between human, bovine and rabbit $\mathrm{Pg}$ molecules. We also put forward suppositions about more structural flexibility of the human zymogen molecule (Nikandrov et al., 1989, 1992).

This problem is still far from being solved. In fact, there are only a few articles on acidic transformations of human and swine $\mathrm{Pg}$ using intrinsic tryptophan fluorescence (Rodier, 1976; 
Zyma et al., 1981). In the present study, we used an intrinsic tryptophan fluorescence method and examined tryptophan-containing sites of human, rabbit and bovine $\mathrm{Pg}$ molecules in a wide range of solvent $\mathrm{pH}$. In some experiments the method of selective quenching of fluorescence was used.

\section{MATERIALS AND METHODS}

The human Pg samples were prepared from a $\beta$-globulin enriched blood fraction by affinity chromatography on lysine-sepharose (Brockway and Castellino, 1971). Rabbit and bovine Pg samples were purified from blood plasma by affinity chromatography on lysine-polymersilochrome (Demidchik, 1985). Specific activity of $\mathrm{Pg}$ samples, determined by a caseinolytic method (Taylor and Tomar, 1970), after activation of human plasminogen and rabbit Pgs by SK and bovine Pg by urokinase, comprised 25 caseinolytic units per $\mathrm{mg}$ of protein. Protein concentration in purified $\mathrm{Pg}$ samples was measured spectrophotometrically on the value of absorption of water solutions with $280 \mathrm{~nm}$. taking $A_{1 \mathrm{~cm}}^{1 \%} 17.0 ; 18.1,15.3$ for human, rabbit and bovine Pgs, respectively (Wohl et al., 1977; Summaria et al., 1973).

Homogeneity of the obtained samples of purified proteins was proved by electrophoresis in $12.5 \%$ polyacrylamide gel in the presence of sodium dodecyl sulfate (Weber and Osborn, 1969).

The spectra of tryptophan fluorescence were taken on a Fica 55 spectrofluorometer with excitation of $\lambda=296 \mathrm{~nm}$. Fluorescence quenching was measured with addition of $3 \mathrm{M}$ solution of $\mathrm{CsCl}, \mathrm{NaNO}_{3}$ or acrylamide to $2 \mathrm{ml}$ of $\mathrm{Pg}$ solution $\left(1.6-2.1 \times 10^{-6} \mathrm{M}\right)$ immediately before measurement (aliquots of quencher solutions were $5-10 \mu 1)$. The data on quenching were processed according to the Stern-Volmer equation, applying corrections for reabsorption for $\mathrm{NaNO}_{3}$ (Burstein, 1977).

Solution $\mathrm{pH}$ was determined with the use of the following buffering systems: $\mathrm{pH} 1-2,0.05 \mathrm{M}$ $\mathrm{KCl}-\mathrm{HCl}$; pH 3-8, $0.05 \mathrm{M}$ citric acid$\mathrm{Na}_{2} \mathrm{HPO}_{4} ; \quad$ pH 9, $0.05 \mathrm{M} \quad \mathrm{KH}_{2} \mathrm{PO}_{4}-\mathrm{Na}_{2} \mathrm{~B}_{4} \mathrm{O}_{7}$; pH 10-11,0.05 M Na $\mathrm{CO}_{3}-\mathrm{HCl}$; pH 12, $0.1 \mathrm{M}$ $\mathrm{Na}_{2} \mathrm{HPO}_{4}-\mathrm{NaOH}$. All the buffering systems contained in addition $0.1 \mathrm{M} \mathrm{NaCl}$.

All measurements were repeated not less than four times.

The following materials were used: SK preparation "Streptase" (Behringwerke AG,
Germany), urokinase (Iskra-Industry, Japan), acrylamide, L-lysine, polyacrylamide gel reactants (Reanal, Hungary), disodium dodecyl sulfate (Serva, Germany), CNBr-Sepharose (Pharmacia, Sweden). Other reagents were Russian production (analytical grade). L-lysine$\mathrm{CNBr}-$ Sepharose was synthesized from L-lysine and $\mathrm{CNBr}$-Sepharose in $0.1 \mathrm{M}$ phosphate buffer pH 9.0 (Brockway and Castellino, 1971).

\section{RESULTS AND DISCUSSION}

Proceedings from the obtained data, the tryptophan-containing sites of molecules are in a stable state with pH 5-8 for human $\mathrm{Pg}$ (Fig. 1), pH 7-9 for rabbit $\mathrm{Pg}$ (Fig. 2), and pH 6-9 for bovine Pg (Fig. 3). Beyond these $\mathrm{pH}$ ranges tryptophan fluorescence quenches.

Thus, the value of " $q$ " for these three zymogens decreased by $42-50 \%$ with $\mathrm{pH} 1.0$. Taking into account changes of value of quantum yield (q) of zymogen fluorescence with $\mathrm{pH}$ from 7.0 to 1.0 shift, we determined the value of $\mathrm{p} K_{a}$ (according to the general rule of ionization constant evaluation for spectrophotometric measurements, Albert and Sergent, 1964), which comprised 3.0, 4.37, and 3.92 for human, rabbit and bovine Pgs, respectively. It enables us to conclude that tryptophan fluorescence quenching in acid medium for rabbit $\mathrm{Pg}$ is causcd by interaction with protonated carboxyl of Glu or Asp residues. At the same time, $\mathrm{p} K_{a}$ of human and bovine zymogens is considerably less than that of Glu and Asp side groups in proteins,

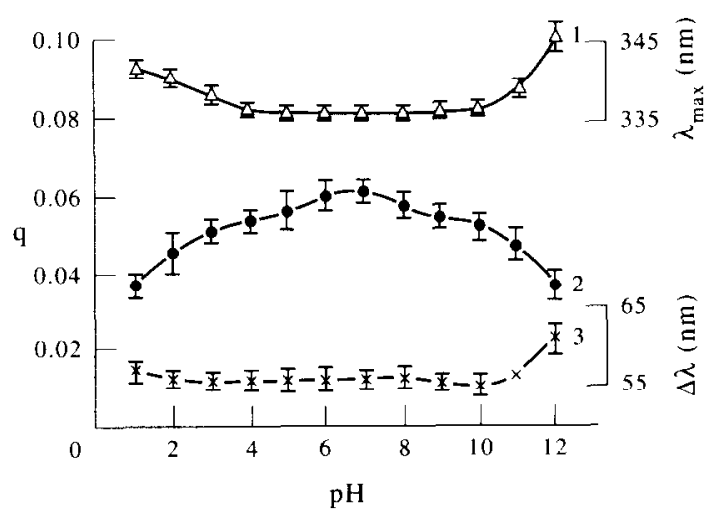

Fig. 1. The changes of quantum yield (q, 1), position of the maximum $\left(\lambda_{\max }, 2\right)$ and the half-widths $(\Delta \lambda, 3)$ of the tryptophan fluorescence spectra of human $\mathrm{Pg}$ at different solution pHs. The solvents are $0.05 \mathrm{M} \mathrm{KCl}-\mathrm{HCl}$ (for

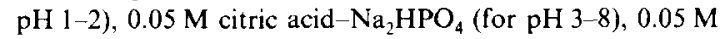
$\mathrm{KH}_{2} \mathrm{PO}_{4}-\mathrm{Na}_{2} \mathrm{~B}_{4} \mathrm{O}_{7}$ (for $\mathrm{pH}$ ), $0.05 \mathrm{M} \mathrm{Na} \mathrm{Na}_{3}-\mathrm{HCl}$ (for $\mathrm{pH} 10-11$ ) and $0.1 \mathrm{M} \mathrm{Na}_{2} \mathrm{HPO}_{4}-\mathrm{NaOH}$ (for $\mathrm{pH} 12.0$ ). $0.1 \mathrm{M}$ $\mathrm{NaCl}$ was added to all buffer systems. 


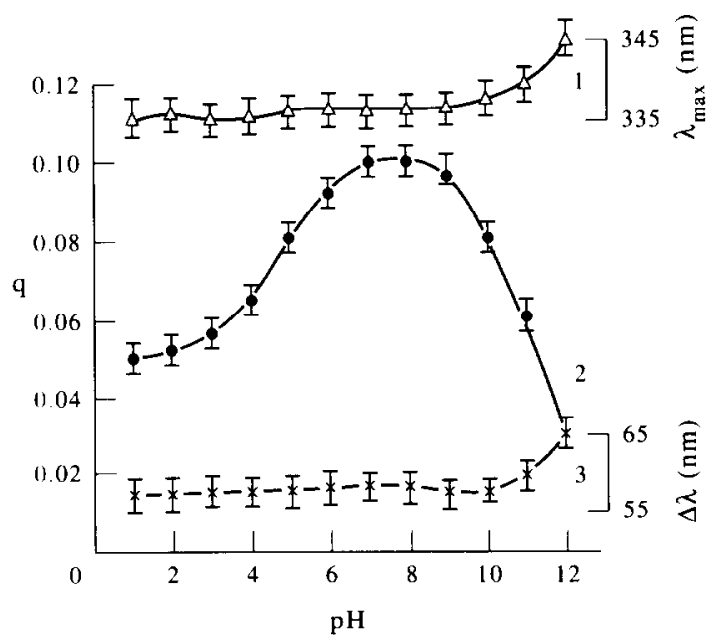

Fig. 2. The dependence of quantum yield (q, 1), position of the maximum $\left(\lambda_{\max }, 2\right)$ and the half-widths $(\Delta \lambda, 3)$ of the tryptophan fluorescence spectra of rabbit $\mathrm{Pg}$ on the $\mathrm{pH}$ solution. The conditions are the same as in Fig. 1 .

namely 4.4-4.6 (Cantor and Schimmel, 1984). It seems, that in molecules of these zymogens tryptophan fluorescence quenching manifests itself in different ways: for example, as a result of interaction between $\alpha$-carboxyl of the $\mathrm{C}$-terminal residue of the molecule, or of protein conformation transition. The latter phenomenon possibly conforms with human $\mathrm{Pg}$ action,

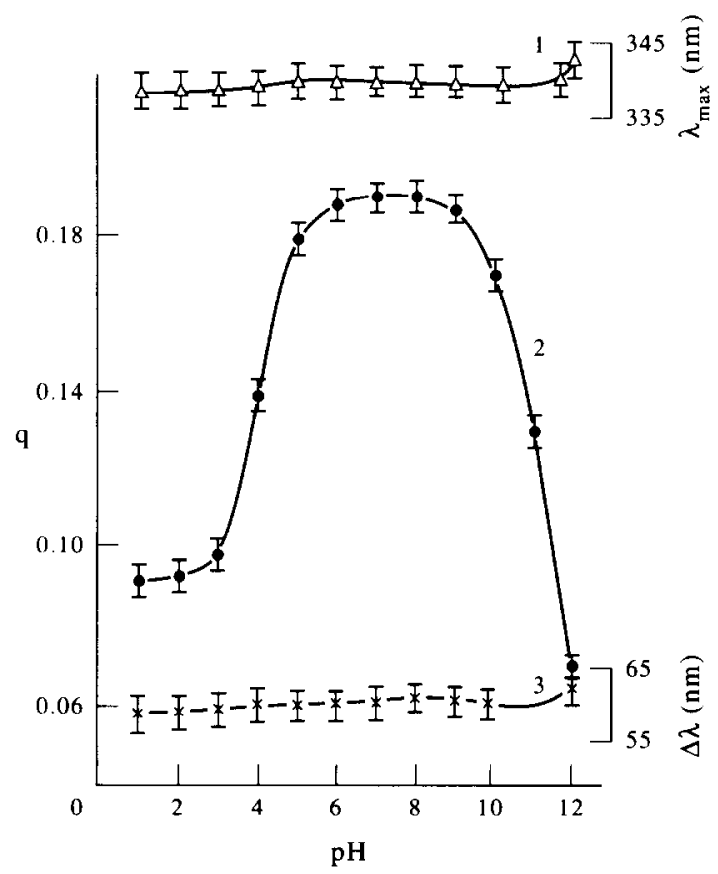

Fig. 3. The influence of solution pH upon the changes of quantum yield (1), position of the maximum (2) and the half-widths (3) of the tryptophan fluorescence spectra of bovine $\mathrm{Pg}$. The conditions are the same as in Fig. 1 . because fluorescence quenching is followed, starting from $\mathrm{pH} 4.0$, by a significant batochromic shift of $\lambda_{\max }$ (Fig. 1). This enables us to suggest increased availability of tryptophan residues for solvent. It conforms with more effective fluorescence quenching, especially by the $\mathrm{NO}_{3}^{-}$anion with $\mathrm{pH} 3.0$, compared with pH 7.0 (see Table 1), and with a significant increase of $I_{355} / I_{328}$ ratio (Fig. 4). Taking into consideration rabbit $\mathbf{P g}$, the Stern-Volmer constant is somewhat lower with $\mathrm{pH} 3.0$, than that with $\mathrm{pH}$ 7.0. In general, the degree of fluorescence quenching $(\%)$ is slightly higher in an acid medium than with $\mathrm{pH} 7.0$, this is especially characteristic of hovine Pg. However, the absence of changes of $\lambda_{\max }$ and fluorescence spectrum half-widths $(\Delta \lambda)$ in acid medium in rabbit and bovine Pgs (Figs 2 and 3) enables us to presuppose that there are no significant structural transformations of tryptophan-containing sites in the molecules of these Pgs.

Tryptophan fluorescence is quenched in all three zymogens when the solution $\mathrm{pH}$ is higher than 9.0. But with $\mathrm{pH} 12.0$ the degree of quenching differs among these proteins: for human $\mathrm{Pg}$ quenching reaches $10 \%$ (Fig. 1), while for rabbit and bovine Pgs this value decreases by 72 and $68 \%$, respectively (Figs 2 and 3 ).

The $\mathrm{p} K_{a}$ values of quenching groups, calculated from " $\mathrm{q}$ " alterations in $\mathrm{pH}$ range $8-12$, comprise $9.86,10.9$ and 11.0 for human, rabbit and bovine Pgs, accordingly. For rabbit and bovine Pgs these values practically equal the $\mathrm{p} K_{a}$ of tyrosine residue ionization in $\mathrm{Pg}$ molecules, i.e. 11.2 (Nikandrov et al., 1989, 1992). This enables us to conclude that tryptophan fluorescence quenching in these zymogens is caused by tyrosyl ionization. For human $\mathrm{Pg}$, the $\mathrm{p} K_{a}$ value, derived from tryptophan fluorescence quenching, is close to the $\mathrm{p} K_{u}$ of ionization of six strongly ionized tyrosine residues, i.e. 10.2 (Nikandrov et al., 1989, 1992). Consequently, these three Pgs share a basic mechanism of tryptophan fluorescence quenching in an alkaline medium.

In an alkaline medium all the Pgs under study produce a batochromic shift of $\lambda_{\max }$, highly manifested in human and rabbit zymogens (Figs 1 and 2). But only in rabbit Pg, q and $\lambda_{\max }$ changes are parallel, while in the other cases $\lambda_{\max }$ shifts only with $\mathrm{pH}>11.0$. The same pattern applies for $\Delta \lambda$. However, it was particularly pronounced with rabbit Pg. These phenomena support the assumption that in an alkaline medium the structure of tryptophan-containing 
Table I. Stern-Volmer constant values $\left(\mathrm{mol}^{-1}\right)$ of the human, rabbit and bovine Pgs, tryptophan fluorescence quenching under change of solution $\mathrm{pH}$

\begin{tabular}{|c|c|c|c|c|c|c|c|c|c|}
\hline \multirow[b]{2}{*}{ Pgs } & \multicolumn{3}{|c|}{$\begin{array}{l}\text { Quenching by } \mathrm{Cs}^{+} \\
\text {at a solution } \mathrm{pH} \text { of }\end{array}$} & \multicolumn{3}{|c|}{$\begin{array}{l}\text { Quenching by } \mathrm{NO}_{3}^{-} \\
\text {at a solution } \mathrm{pH} \text { of }\end{array}$} & \multicolumn{3}{|c|}{$\begin{array}{l}\text { Quenching by acrylamide } \\
\text { at a solution } \mathrm{pH} \text { of }\end{array}$} \\
\hline & 3.0 & 7.0 & 11.0 & 3.0 & 7.0 & 11.0 & 3.0 & 7.0 & 11.0 \\
\hline Human & 1.5 & 1.6 & 1.1 & 10.0 & 7.5 & 5.4 & 2.9 & 2.5 & 3.0 \\
\hline Rabbit & - & - & - & 3.0 & 10.4 & 5.0 & 5.5 & 6.0 & 2.9 \\
\hline Bovine & - & - & - & 7.5 & 6.5 & 5.1 & 4.6 & 3.2 & 2.2 \\
\hline
\end{tabular}

$\mathrm{Pg}$ sites is partially disorganized, while tryptophan residues become more available for solvent. Taking into consideration changes of $\mathrm{I}_{355} / \mathrm{I}_{328}$ ratio, it could be applied to human and rabbit Pgs (Fig. 4). Besides with pH 9-12 these ratio changes conform with $\lambda_{\max }$ shifts. At the same time, for rabbit $\mathrm{Pg}$ these shifts do not comply with the decreased effectiveness of fluorescence quenching when $\mathrm{pH}$ equals 11.0 (see Table 1). We could presuppose that the latter phenomenon depends on the width of "pockets", in which tryptophan residues are localized. In fact, the radius of an $\mathrm{OH}^{-}$ion is $0.15 \mathrm{~nm}$, whereas that of a $\mathrm{NO}_{3}^{-}$ion is not less than $0.19 \mathrm{~nm}$.

\section{CONCLUSION}

Thus, we determined differences in mobility of tryptophan-containing sites of human, bovine and rabbit $\mathrm{Pg}$ molecules. When $\mathrm{pH}$ shifts from 7.0 to 1.0 , human $\mathrm{Pg}$ molecules experience a significant conformational transition of these sites, judging by parameters of tryptophan

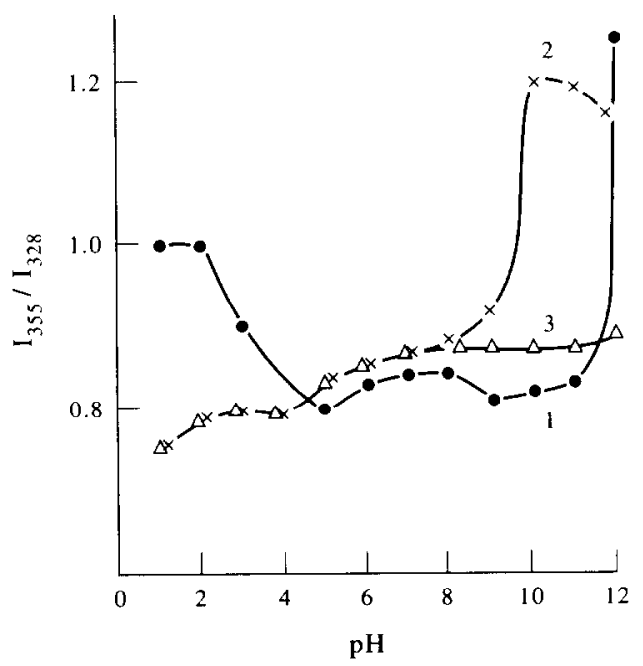

Fig. 4. The values of $I_{355} / I_{328}$ ratio (ratio "fluorescence intensivity at $355 \mathrm{~nm}$ band: fluorescence intensivity at $328 \mathrm{~nm}$ band") for human (- - ), rabbit ( $-\mathrm{X}-$ ) and bovine $(-\triangle-)$ Pgs under changes in solution $\mathrm{pH}$. fluorescence spectra and the effectiveness of its selective quenching. These transitions are manifested with $\mathrm{pH}<4.0$. In an alkaline medium tryptophan-containing sites of rabbit $\mathrm{Pg}$ are more labile in structure, as their transition begins even with a $\mathrm{pH}>9.0$, while conformational transitions of tryptophan-containing sites in human $\mathrm{Pg}$ are manifested only with $\mathrm{pH}>11.0$.

According to previous data (Landmann, 1976), the formation of stoichiometric stable complexes between SK and human Pg is possible in a $\mathrm{pH}$ range of 4-10. Consequently, structural reorganization of the human $\mathrm{Pg}$ molecule could account for absence of these complexes with $\mathrm{pH} \leqslant 3.0$ and $>10.5$.

The bovine $\mathrm{Pg}$ molecule, it seems, has the most fixed structure. Considering rabbit $\mathrm{Pg}$, some peculiarities of the state of tryptophancontaining sites make it different from human $\mathrm{Pg}$ in an acid medium, and from human and bovine Pgs in an alkaline medium. It should be noted, that data on circular dichroism spectroscopy illustrate its specific interaction with SK, in contrast to human and bovine zymogens (Nikandrov et al., 1992). It proves the necessity of further and more detailed studies on rabbit Pg-SK interaction.

Acknowledgements-This research was sponsored by the Foundation of Fundamental Researches, Republic Belarus.

\section{REFERENCES}

Ablondi F. B. and Hagan J. J. (1957) Comparison of certain properties of human plasminogen and "proactivator". Proc. Soc. exp. Biol. Med. 95, 195-200.

Ablondi F. B. and Hagan J. J. (1958) Studies on specificity of streptokinase. Proc. Soc. exp. Biol. Med. 99, 769-772.

Albert A. and Sergent E. (1964) Ionization Constants of Acids and Alkalines. Khimia, Moscow-Leningrad (in Russian).

Brockway W. J. and Castellino F. (1971) The mechanism of the inhibition of plasmin activity by $\epsilon$-amino caproic acid. J. biol. Chem. 246, 4641-4647.

Burstein E. A. (1977) Intrinsic Fluorescence of Protein (Nature and Application). VINITI, Moscow (in Russian). 
Castellino F. J. (1979) A unique enzyme-protein substrate modifier reaction: plasmin:streptokinase interactions. Trans. Int. biochem. Soc. 1, 1-5.

Cantor Ch. R. and Schimmel P. R. (1980) Biophysical Chemistry. Part I. W. H. Freeman \& Co, San Francisco.

Demidchik N. V. (1985) Preparation of rabbit and bovine plasminogens by affinity chromatography on lysinepolymer-silochrome. In Streptokinase in the Regulation of Hemostatic and Antihemostatic Systems (Edited by Savchenko N. E. et al.), pp. 109-113. Minsk.

Jackson K. W., Esmon N. and Tang J. (1980) Structural homology of streptokinase with serine proteases and possible relationships with staphylokinase. In Regulation of Coagulation. pp. 515-525. New York.

Kristensen P., Larsson I..J., Nielsen I.. S., GrondahlHansen J., Andreasen P. A. and Dano K. (1984) Human endothelial cell contain one type of plasminogen activator. FERS Iett. 168, 33-37

Laiho M. and Keski-Oja J. (1989) Growth factors in the regulation of pericellular proteolysis: a review. Cancer Res. 49, 2533-2553

Landmann H. (1976) Biochemische Aspekte der Streptokinasewirkung. Folia Haemat. 103, 437-444.

Niedbala N. J. and Sartorelli A. C. (1989) Regulation by epidermal growth factor of human squamous cell carcinoma plasminogen activator-mediated proteolysis of extracellular matrix. Cancer Res. 49, 3302-3309.

Nikandrov V. N., Vorobyova G. V., Demidchik N. V. and Yankovskaya G. S. (1989) Conformation peculiarities of human, bovine and rabbit plasminogen molecules in a solution. Doklady Acad. Sci. BSSR. 33, 664 667. (in Russian).

Nikandrov V. N., Vorobyova G. V., Yankovskaya G. S. and Demidchik N. V. (1992) Conformation ability test of human, rabbit and bovine plasminogens and their specific interaction with streptokinase. Int. J. biol. Macromol. 14, 229-234.

Paoni N. F. and Castellino F. J. (1979) A comparison of the urokinase activation properties of the native and lower molecular weight forms of sheep plasminogen. J. biol. Chem. 251, 2064-2070.

Reddy K. N. N. (1988) Streptokinase-biochemistry and clinical application. Enzyme 40, 79-89.

Rodier F. (1976) Proprietes spectrales du plasminogene porcin. Ftude de la transition acide. Fur. I. Biochem. 63, 553-562.

Schick L. A. and Castellino F. J. (1973) Interaction of streptokinase and rabbit plasminogen. Biochemistry 12, 4315.4323.

Summaria L., Arzadon L., Bernabe P. and Robbins K. C. (1973) Isnlation, characterization and comparison of the S-carboxymethyl heavy (A) and light (B) chain derivatives of cat, dog, rabbit and bovine plasmins. J. biol. Chem. 248, 6522-6527.

Summaria L., Arzadon L., Bernabe P. and Robbins K. C. (1974) The interaction of streptokinase with human, cat, dog and rabbit plasminogens. The fragmentation of streptokinase in the equimolar plasminogen-streptokinase complex. J. biol. Chem. 249, 4760-4769.

Taylor F. B. and Tomar R. H. (1970) Streptokinase. In Methods in Enzymology. Vol. 19, pp. 807-821. Academic Press, New York.

Weber K. and Osborn M. (1969) The reliability of molecular weight determinations by dodecyl sulfatepolyacrylamide gel electrophoresis. $J$. biol. Chem. 244, 4406-4412.

Wohl R. C., Arzadon L., Summaria L. and Robbins K. C. (1977) Comparison of the esterase and human plasminogen activator activities of various activated forms of human plasminogen and their equimolar streptokinase complex. J. biol. Chem. 252, 1141-1147.

Wulf R. J. and Mertz E. T. (1969) Studies on plasminogen. VIII. Species specificity of streptokinase. Can. J. Biochem. 47, 927-931.

Zyma V. L., Gruzin D. V. and Matsuy S. P. (1981) Fluorescent studies in conformation states of human plasminogen. I. pH effect. Ukr. Biochim. Zhurn. 53, 22-25. (in Russian). 